Research article

\title{
Prophylactic cranial irradiation in small cell lung cancer: a systematic review of the literature with meta-analysis Anne-Pascale Meert ${ }^{1}$, Marianne Paesmans ${ }^{1}$, Thierry Berghmans ${ }^{1}$, Benoît Martin ${ }^{1}$, Céline Mascaux ${ }^{1}$, Frédéric Vallot ${ }^{1}$, Jean-Marc Verdebout ${ }^{3}$, Jean-Jacques Lafitte ${ }^{2}$ and Jean-Paul Sculier*1
}

\author{
Address: ${ }^{1}$ Service de Médecine, Institut Jules Bordet, Bruxelles, Belgique, ${ }^{2}$ Service de Pneumologie et d'Oncologie Thoracique, CHU Calmette, \\ Lille, France and ${ }^{3}$ Service d'Anatomo-Pathologie, Institut Jules Bordet, Bruxelles, Belgique \\ E-mail: Anne-Pascale Meert - ap.meert@bordet.be; Marianne Paesmans - marianne.paesmans@bordet.be; \\ Thierry Berghmans - thierry.berghmans@bordet.be; Benoît Martin - benoit.martin@bordet.be; Céline Mascaux - celinemascaux@yahoo.fr; \\ Frédéric Vallot - Frederic.Vallot@ulb.ac.be; Jean-Marc Verdebout - verdebout@bordet.be; Jean-Jacques Lafitte - jjlafitte@chru-lille.fr; Jean- \\ Paul Sculier* - sculier@bordet.be \\ *Corresponding author
}

This article is available from: http://www.biomedcentral.com//47/-2407///5

(c) 200 I Meert et al, licensee BioMed Central Ltd.

\begin{abstract}
Purpose: A systematic review of the literature was carried out to determine the role of prophylactic cranial irradiation (PCI) in small cell lung cancer (SCLC) .

Methods: To be eligible, full published trials needed to deal with SCLC and to have randomly assigned patients to receive $\mathrm{PCl}$ or not. Trials quality was assessed by two scores (Chalmers and ELCWP).

Results: Twelve randomised trials (I547 patients) were found to be eligible. Five evaluated the role of $\mathrm{PCl}$ in SCLC patients who had complete response (CR) after chemotherapy. Brain CT scan was done in the work-up in five studies and brain scintigraphy in six. Chalmers and ELCWP scores are well correlated $(p<0.001$ ), with respective median scores of 32.6 and $38.8 \%$. This metaanalysis based on the available published data reveals a decrease of brain metastases incidence (hazard ratio (HR): 0.48; $95 \%$ confidence interval $(\mathrm{Cl}): 0.39-0.60$ ) for all the studies and an improvement of survival (HR: 0.82; $95 \% \mathrm{Cl}$ : $0.7 \mathrm{I}-0.96$ ) in patients in $\mathrm{CR}$ in favour of the $\mathrm{PCl}$ arm. Unfortunately, long-term neurotoxicity was not adequately described .

Conclusions: $\mathrm{PCl}$ decreases brain metastases incidence and improves survival in CR SCLC patients but these effects were obtained in patients who had no systematic neuropsychological and brain imagery assessments. The long-term toxicity has not been prospectively evaluated. If $\mathrm{PCl}$ can be recommended in patients with SCLC and CR documented by a work-up including brain CT scan, data are lacking to generalise its use to any $C R$ situations.
\end{abstract}

\section{Introduction}

Small cell lung carcinoma (SCLC) has a very poor prognosis when untreated. The development of chemothera- py, with or without chest radiotherapy, has allowed to obtain survival improvement and a small percentage of cures. However the majority of the patients relapse and 
only $<25 \%$ of complete responders will be long-term survivors [1].

The central nervous system (CNS) is a frequent site of relapse. About $10 \%$ of the patients initially present with brain metastases. The two-year cumulative risk rises to $\geq$ $50 \%$ [2] and CNS metastases are found in up to $65 \%$ of patients at autopsy [3]. The median survival time after brain metastases diagnosis is 4 to 5 months. Because the blood-brain barrier has been considered to protect the CNS from most cytotoxic agents and as SCLC is very radiosensitive, the role of prophylactic brain irradiation (PCI) has been studied in several trials. The results of the randomised trials show that PCI reduces the frequency of brain metastases although survival is not consistently improved. Some data suggest that the gain in survival is restricted to patients in complete remission (CR). A recently published meta-analysis [4] of PCI for SCLC in patients with CR after chemotherapy has analysed the data of 7 randomised studies (including one abstract and one unpublished study) concerning a total of 987 patients (526 treated with PCI and 461 controls). The relative risk (RR) of death in the treatment group as compared to the control group was 0.84 (95\% confidence interval CI: 0.73 to $0.97 ; p=0.01$ ). $\mathrm{PCI}$ decreased also the cumulative incidence of brain metastases (RR: 0.46; CI $95 \%$ : 0.38 0.57 ; $<0.001$ ). Unfortunately the authors have not mentioned the performance of cerebral imagery (CT scan or MRI) in the work-up or the follow-up and have not reviewed the cerebral toxicity of PCI. Some articles have dealt with this question. Johnson [5] reported 20 longterm SCLC survivors with a median follow-up of 6 years (2.4 to 10.6 y). Fifteen SCLC were treated by PCI, 2 by therapeutic cranial irradiation and 3 had no cranial irradiation. Fifteen had neurologic complaints (memory loss, walking or writing difficulties, weakness...), 15 had abnormal brain CT scan (ventricular dilatation, brain atrophy...) and 12 had abnormal mental status examination. Neurologic abnormalities seemed thus to be very common in long-term survivors SCLC and may be more prominent in patients having received high-doses chemotherapy or treated with large brain radiotherapy fractions. Lee [6] reported 3 cases of dementia, confusion and ataxia over 24 patients who received PCI. There was no toxicity in the control group. Toxicity appeared 2.5 years after PCI, the follow-up ranging from 37 to 74 months. In the Chake's study [7], five out of seven patients had progressive dysfunction leading to death in 1 to 26 months after PCI. Foncesca [8] related $14 \%$ leucoencephalopathy in patients with SCLC who received PCI. The mean time of onset of symptoms was 357 days, the median follow-up time being 59 months. Symptoms consisted of intellectual change, memory loss and motor abnormalities. Laukkanen [9] related 60 \% memory loss but no dementia two years after PCI. In the Licciardelo study [10], severe neurologic toxicities occurred in two of 15 patients (2.5 and 30 months after PCI). Finally, Van Oosterhout [11] reported no statistical evidence for additional neurotoxicity (follow-up of 2 years) in a series of 51 patients whatever they had received or not PCI. But there was difference in the neuro-psychological examination between patients and matched healthy controls, that might indicate that cognitive impairment is partly disease-related (probably due to emotional distress and deteriorated physical conditions). All these studies being taken in consideration, the problem of cerebral toxicity remains unclear, leading to controversy about the indications of PCI in SCLC.

The purpose of the present article is to assess the role of PCI in SCLC by performing a syste-matic review of the randomised trials published in the literature. A qualitative evaluation of their methodology was performed, including brain imagery work-ups and neuropsychological assessment as well as an aggregation (meta-analysis) of survival and brain relapse results.

\section{Materials and Methods \\ Trials selection}

To be eligible for the systematic review, trials needed to deal with SCLC exclusively, to have randomly assigned patients to receive prophylactic cranial irradiation or not and to have been published as a full paper in the French or English language literature before January 2000.

Articles were identified by an electronic search (Medline) using the keywords "small cell lung carcinoma" and "prophylactic cranial irradiation" completed by the personal bibliography of one of the authors and by the references reported in the selected studies.

\section{Methodological assessment}

To assess the trial methodology, nine investigators, including six physicians, one biostatistician, one biologist and one pathologist read each publication, guarantying the critical reading of the selected articles. They were then scored according to two quality scales: the score proposed by Chalmers et al. [12] and the score proposed by the European Lung Cancer Working Party (ELCWP) $[13,14]$ as described in Appendix A. The participation of many readers was a guarantee for the correct reading of the articles. The Chalmers score evaluates two dimensions of quality: the internal (scientific) and external (generalisability of results) validities, with respectively maximal scores of 63 and 25 points (the total being 88 points). The ELCWP score assesses two quality aspects: the protocol design (as usually reported in the patients and methods section of the publication) and the analysis performance (as reported in the results section) with maximal scores of 70 and 80 points respectively (with an 
overall maximum of 150 points). Each item was quoted using an ordinal scale (possible values: 2,1 or o). When an item was not applicable in a trial, its theoretically attributable points were not taken into account in the total of the concerned category. As the items were defined by data that could objectively be found in the article and did not require a subjective judgement, the score of each item was consensually determined in meetings where at least two thirds of the investigators needed to be present. The final score was expressed in percentage ranging from o to $100 \%$, higher values reflecting a larger application of methodological standards.

\section{Statistical methods}

The results of a study were considered as "positive" if the $p$ value for the statistical test comparing the survival distributions between arms was $<0.05$ in favour of the experimental arm. In the other situations (statistically significant survival benefit for the control arm or non statistically significant difference in survival distributions), it was called "negative". The same method was used to evaluate the time to relapse in the brain. The correlation between the quality scores, or two other continuous variables, was measured by the Spearman ranks correlation coefficient. Its significance was assessed by testing a null hypothesis of equality to zero of this coefficient. Non-parametric Mann-Whitney (for binary varia- bles) or Kruskal-Wallis (for multiple classes variables) tests were performed to compare quality scores distributions according to the value of the considered discrete variable. For the quantitative aggregation of the survival results, we measured the treatment effect by the hazard ratio (HR) between the survival distribution, according to a method that we have previously reported [15]. For each trial, this HR was estimated by a method depending on the results provided in the publications. The most accurate method consisted to retrieve the HR estimate and its confidence interval from the reported results or to calculate them directly using parameters given by the authors: the confidence interval for the HR, the log-rank statistics or its p value or the O-E statistic (difference between numbers of observed and expected events). If not available, we looked for the total number of events and the log-rank statistic or its p value allowing calculation of an approximation of the HR estimate. Finally, if the exploitable data were in the format of graphical representations of the survival distributions, we extracted survivals rates at some specified times in order to reconstruct the HR estimate and its variance with the assumption that the rate of patients censored was constant during the study follow-up. By convention a $\mathrm{HR}<1 \mathrm{im}-$ plied a survival benefit for the experimental arm. The same method was used for time to relapse of the brain (assessing brain metastases incidence).

Table I: Trials characteristics

\begin{tabular}{|c|c|c|c|c|c|c|}
\hline Authors & Dates & Stage & $\begin{array}{l}\text { Cerebral } \\
\text { work-up }\end{array}$ & $\mathrm{PCl}$ (Gray) & $\begin{array}{l}\text { Timing of } \mathrm{PCl} \\
\text { administration }\end{array}$ & $\mathrm{N}$ patients \\
\hline Jackson [18] & 1977 & I & 2 & 30 & I & 29 \\
\hline Beiler [24] & 1979 & I & 2 & 24 & 1 & 54 \\
\hline Hansen [22] & 1980 & 2 & 2 & 40 & 3 & 109 \\
\hline Maurer [26] & 1980 & I & 2 & 30 & I & 153 \\
\hline Eagan [20] & 1981 & 2 & I & 36 & 3 & 30 \\
\hline Aisner [27] & 1982 & I & I & 30 & 2 & 29 \\
\hline Seydel [2I] & 1985 & 2 & 2 & 30 & I & 217 \\
\hline Niiranen [25] & 1989 & 2 & 2 & 40 & I & 51 \\
\hline Ohonoshi [23] & 1993 & I & I & 40 & 2 & 46 \\
\hline Arriagada [16] & 1995 & I & I & 24 & 2 & 294 \\
\hline Gregor [19] & 1997 & 2 & 3 & $8-40$ & 2 & 314 \\
\hline Laplanche [I7] & 1998 & I & I & 24 & 2 & 211 \\
\hline
\end{tabular}

Stage: I: all 2: limited disease Cerebral work-up: I: brain CT scan 2: brain scintigraphy 3: clinical Timing: I: at initiation of chemotherapy 2: CR consolidation 3: consolidation only 
Table 2: Quality Scores assessment

\begin{tabular}{|c|c|c|c|c|c|c|c|c|}
\hline \multirow[t]{2}{*}{ Authors } & \multicolumn{3}{|c|}{ ELCWP Score } & \multicolumn{3}{|c|}{ Chalmers Score } & \multirow[t]{2}{*}{ SMA } & \multirow[t]{2}{*}{ BMI MA } \\
\hline & PD (\%) & $\mathrm{AP}(\%)$ & Total (\%) & IV (\%) & EV (\%) & Total (\%) & & \\
\hline Arriagada [16] & 81.0 & 70.9 & 70.3 & 84.2 & 54.5 & 75.9 & Yes & Yes \\
\hline Laplanche [17] & 59.3 & 58.1 & 58.7 & 50.0 & 40.9 & 47.6 & Yes & Yes \\
\hline Jackson [18] & 30.3 & 35.7 & 33.2 & 21.0 & 27.2 & 22.8 & Yes & Yes \\
\hline Gregor [19] & 69.0 & 49.6 & 58.7 & 59.5 & 27.2 & 51.1 & Yes & Yes \\
\hline Eagan [20] & 33.0 & 40.4 & 36.9 & 28.5 & 20.4 & 24.7 & Yes & No data \\
\hline Seydel [2I] & 25.0 & 28.0 & 26.6 & 14.3 & 13.6 & 14.1 & Yes & Yes \\
\hline Hansen [22] & 52.3 & 31.6 & 41.3 & 47.6 & 40.9 & 45.9 & Yes & No data \\
\hline Ohonoshi [23] & 38.0 & 43.1 & 40.7 & 42.8 & 54.5 & 47 & Yes & Yes \\
\hline Beiler [24] & 25.4 & 23.1 & 24.2 & 33.3 & 13.6 & 28.2 & Yes & Yes \\
\hline Niiranen [25] & 48.9 & 34.7 & 41.3 & 40.4 & 27.3 & 37 & Yes & Yes \\
\hline Maurer [26] & 36.9 & 31.1 & 33.8 & 23.8 & 13.6 & 22.3 & Yes & Yes \\
\hline Aisner [27] & 37.4 & 28.7 & 32.8 & 10.5 & 13.6 & 11.4 & No data & Yes \\
\hline Mean & 44.7 & 39.6 & 41.5 & 38.0 & 28.9 & 35.7 & & \\
\hline Median & 37.7 & 35.2 & 38.8 & 36.9 & 27.2 & 32.6 & & \\
\hline
\end{tabular}

PD : protocol designed AP : analysis performance ELCWP : European Lung Cancer Working Party IV : internal validity EV : external validity SMA : survival meta-analysis (studies evaluables) BMI : brain metastasis incidence meta-analysis (studies evaluables)

\section{Results}

A total of 12 randomised trials [16-27] published between 1977 and 1998 were found to be eligible for the present systematic review. Their main characteristics are summarised in table 1 . The total number of eligible patients included was 1547; the number of patients by study ranged from 29 to 314 patients (with a median of 81 patients). Seven hundred and ninety eight patients were randomly assigned to the PCI group and 749 patients to the control group. Five studies (894 patients) $[16,17,19,23,27]$ evaluated the role of PCI in SCLC patients who had a complete response after induction chemotherapy. Five studies [18, 21, 24, 25, 26] assessed the role of PCI administered at induction chemotherapy in patients considered as free of brain metastases. In two studies [20, 22], PCI was given as treatment consolidation at the end of chemotherapy before response evaluation. Seven trials $[16,17,18,23,24,26,27]$ included SCLC patients at all stages of this disease and five studies $[19,20,21,22,25]$ only limited disease. Brain CT scan was done at the initial staging work-up in five studies $[16$, $17,20,23,27]$ and brain scintigraphy in six $[18,21,22$, $24,25,26]$. In one study [19], the staging was only based on clinical examination. The dose of cranial irradiation ranged from 24 to $40 \mathrm{~Gy}$ (except in Gregor's study where it was comprised between 8 and $40 \mathrm{~Gy}$ ). Quality score assessments of the studies are shown in table 2. The overall median quality ELCWP score was $38.8 \%$ (ranging from 24.2 to $70.3 \%$ ) with respective protocol design and analyse performance median subscores of $37.7 \%$ (range:
25.0 - 81.0) and $35.2 \%$ (range: 23.1 - 70.9). The linear correlation between protocol design and analyse performance was statistically significant $(\mathrm{Rs}=0.75 ; \mathrm{p}=$ 0.005). The overall median Chalmers quality score was $32.6 \%$ (range: $11.4-75.9 \%$ ). There was a significant correlation between both scores $(\mathrm{Rs}=0.85 ; \mathrm{p}<0.001)$. There was also a significant difference for ELCWP score according to the year of publication $(\mathrm{Rs}=0.71 ; \mathrm{p}=0.01$ ), with better quality score for the new recent studies.

The most poorly described items of the ELCWP scale were the work-ups including neuropsychological tests (with a mean score of $22 \%$ ), the evaluation criteria (27 $\%)$ and the treatment description (33\%) for the internal validity, the prognostic factors for relapse (o \%) or for survival (o \%) and the description of the neurological toxicities (14\%) for the external validity.

Half of the individual studies reported an improvement of time to relapse in the brain assessing incidence brain metastases $[16,18,19,25,26,27]$ in the PCI arm but none showed an advantage in term of survival. For the meta-analysis of brain metastases incidence, data were available in 10 trials. The hazard ratio (HR) was provided in 2, it was calculated from the logrank statistic and he number of events in 7 or from the brain metastases incidence curves in one. The meta-analysis revealed a significant decrease in the incidence of brain metastases when all the studies were considered (fig 1 ) with a hazard ratio (HR) of 0.48 (95\% CI: $0.39-0.60$ ) and when only pa- 


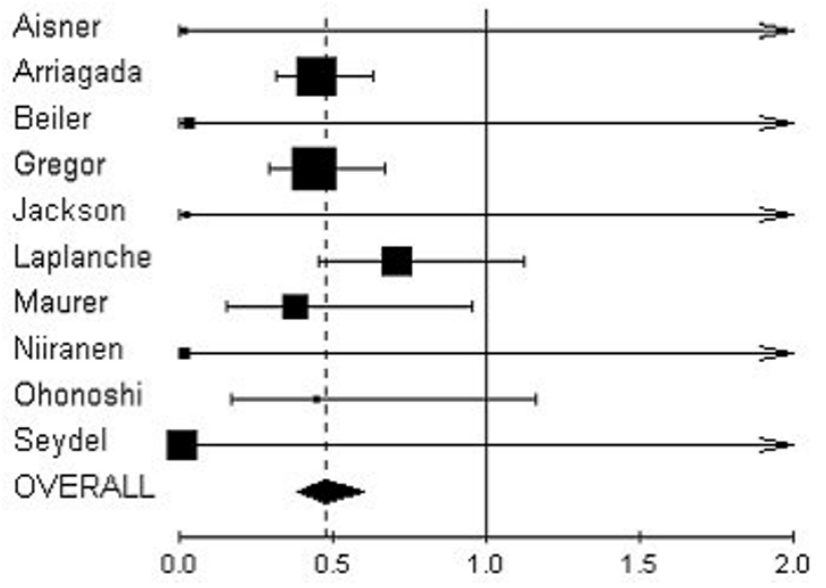

Figure I

Results of the meta-analysis of the studies evaluating the role of $\mathrm{PCl}$ on time to relapse in the brain assessing brain metastases incidence : $\mathrm{HR}: 0.48(95 \% \mathrm{Cl}: 0.39-0.60) \mathrm{NB}$ : the centre of the lozenge gives the combined HR of the metaanalysis and its extremities the $95 \%$ confidence interval.

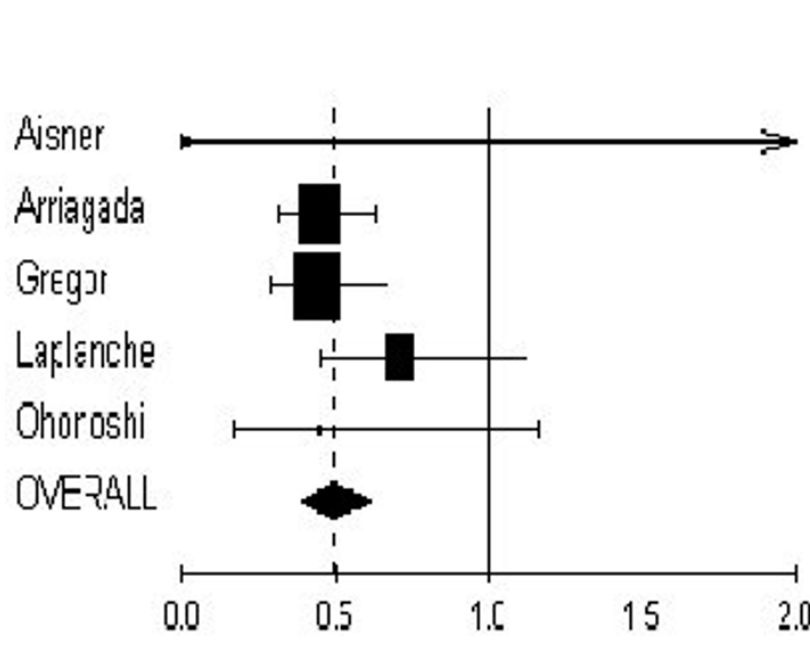

Figure 2

Results of the meta-analysis of the studies evaluating the role of $\mathrm{PCl}$ on time to relapse in the brain assessing brain metastases incidence when patients are in complete response : HR : $0.49(95 \% \mathrm{Cl}: 0.39-0.62)$

tients in CR were considered (fig 2) with a HR of 0.49 (95 \% CI: 0.39-0.62). For the meta-analysis of survival, data were available in 11 trials. The hazard ratio was provided in 3 , it was calculated from the logrank statistic and the number of events in 6 or from the survival curves in 2 . The meta-analysis showed the absence of improvement for survival when all the studies were considered (HR: 0.94; 95 \% CI: 0.87 -1.02) (fig 3) but revealed an improvement in survival when PCI was given to patients in CR (HR: 0.82; 95 \% CI: 0.71 - 0.96) (fig 4).

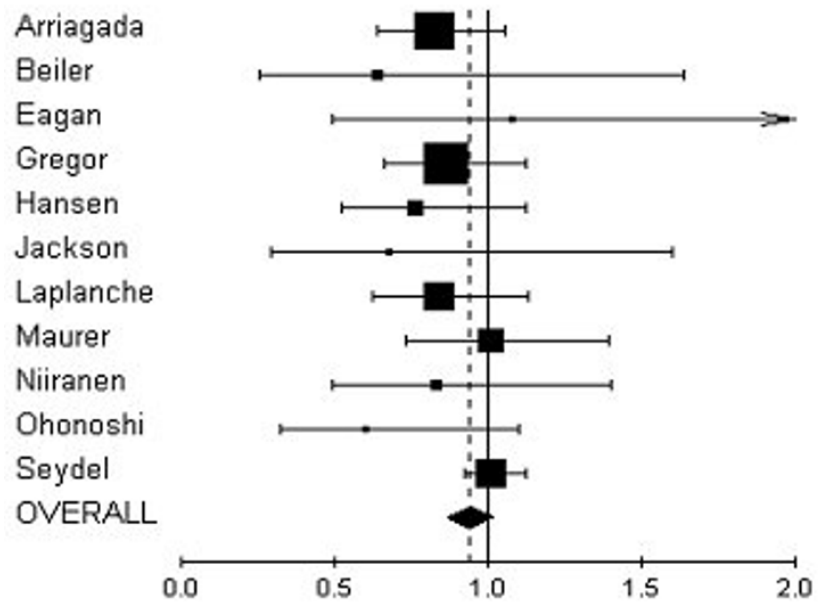

Figure 3

Results of the meta-analysis of the studies evaluating the role of $\mathrm{PCl}$ on survival : $\mathrm{HR}: 0.94(95 \% \mathrm{Cl}: 0.87-\mathrm{I} .02)$

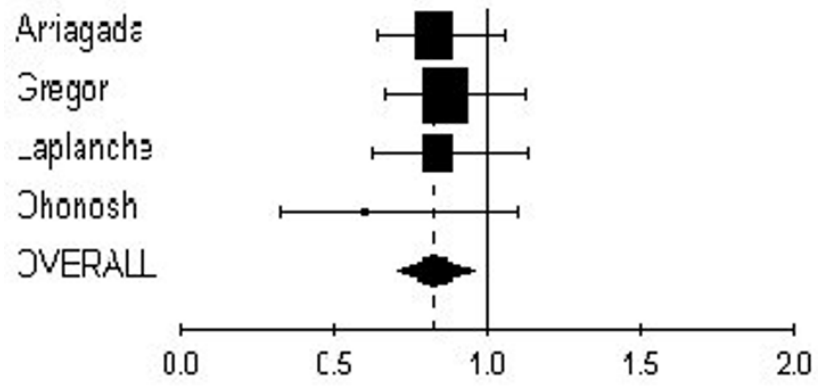

Figure 4

Results of the meta-analysis of the studies evaluating the role of $\mathrm{PCl}$ on survival when patients are in CR : HR : $0.82(95 \%$ $\mathrm{Cl}: 0.7 \mathrm{I}-0.96)$

We also performed some subgroups analysis. The decrease in brain metastases incidence was also present in the subgroups of patients with initial PCI, limited disease, any stage disease or who had brain CT scan at initial staging and just before randomisation for PCI (table 3). Results were not significant for survival in patients with initial PCI, limited disease or who had no brain CT scan before randomisation. Statistical significance was marginal in patients with any stage disease or who had brain CT scan for initially staging or just before randomisation for PCI (table 4).

Toxicity was rarely adequately described. There was no data in four studies. In five trials, authors provided a short narrative description mentioning no or minimal toxicity (as alopecia...); Ohonoshi [23] reported one case of sevenlong-term disease-free survivors who had mem- 
ory disturbance and gait ataxia in the PCI arm. Two trials reported neuropsychological evaluation in a part of the randomised patients. Gregor [19] performed an assessment of cognitive function in $40 \%$ of the randomised patients and showed no difference between the two arms at two years after PCI but without latter data. Arriagada [16] evaluated $60 \%$ of the patients two years after PCI and showed no difference between the two groups.

\section{Discussion}

This systematic review, by pooling all randomised studies comparing treatment of SCLC with or without PCI, revealed a positive effect of PCI. As shown by the metaanalysis, PCI reduced brain metastases incidence and improved survival in patients in CR after chemotherapy (especially when brain CT scan was part of the staging work-up). Unfortunately, the performance of brain imagery (CT scan or MRI) and the long-term assessment of neuropsychological toxicities are not well described in the 12 available trials.

Table 3: Subgroup meta-analysis: role of $\mathrm{PCl}$ on time to relapse in the brain assessing brain metastases incidence ( 10 studies evaluable)

$$
\text { n studies } \quad H R
$$

$\begin{array}{lll}\text { Initial PCI } & 5 & 0.29(0.12-0.7 I) \\ \text { Limited disease } & 3 & 0.43(0.28-0.64) \\ \text { All stages diseases } & 7 & 0.50(0.39-0.65) \\ \text { Brain CT scan for staging } & 4 & 0.52(0.40-0.68) \\ \text { Brain CT scan before randomisation } & 2 & 0.44(0.32-0.62) \\ \text { No CT scan before randomisation } & 2 & 0.5 I(0.38-0.63)\end{array}$

To perform a meta-analysis comparing such heterogeneous trials, we have used a methodology that was similar to our prior systematic reviews $[14,15]$. All trials were assessed by 9 investigators using two quality scores: the Chalmers and the ELCWP scales. The latter scale was adapted to the present topic by introducing some specific changes: in the work-up, brain CT scan or MRI with neuropsychological assessment was needed to have 2 points; in the treatment description, brain irradiation method had to be described; neuropsychological examination results were added in the patients characteristics and the "local control of tumour" item was changed in a "brain metastases incidence" item. The results obtained with the two scales were compared and a significant correlation was observed. There was no quality difference among the publications, allowing quantitative aggregation (meta-analysis) of the results of the individual trials.
The only significant finding in the performed comparisons was an improved quality in favour of more recently published trials, which can be explained by a better knowledge of clinical trials methodology standards over the last years.

Our approach does not however prevent all the potential biases. The most important one is probably the publication bias. Our review took into account only fully published studies. We did not look for unpublished trials and abstracts because the methodology used required data available in full publications only. Meta-analysis based on individual data is considered by some authors as the gold standard [28]. Systematic reviews of the literature and meta-analyses of individual patient data should not be confused. The first approach is only based on the fully published studies and provides an exhaustive and critical analysis of the topic with an adequate methodology based on the criteria of Mulrow [29] and with data aggregation (meta-analysis) when possible. The second approach is in fact a new study taking into account all performed trials on the topic, whatever published or not, requiring individual data update by the investigators. In that latter, publications are mainly used for identification purposes. Our meta-analysis, based on the published data, has allowed us to find the same results for patients in CR as Auperin et al [4] in their individual data meta-analysis. This point supports the validity of our approach. Another potential bias is the language problem: we have restricted our review to articles published in English or French. This selection could favour the positive studies that are most often published in English while the negative ones tend to be more reported in native language [30]. The method of extrapolation of HR needs also to be discussed. When HR were not reported by the authors, they were calculated from the data available in the article and, if not possible, they were extrapolated from the survival curves. This approach might have been associated with errors due to imprecision of the reading.

The brain work-up is often poorly documented. Only five studies reported brain CT scan in the initial evaluation and only in two of them, brain CT scan was done just before randomisation for PCI (when patients were in CR after chemotherapy). So, in the majority of the studies, the CR population could contain patients with asymptomatic brain metastases for which the delivered PCI was in fact a consolidation therapy. To be sure that there are no brain involvement, brain CT scan should have been done just before PCI. In addition, the CR status depends on the type of work-up performed and on the presence of lesions due to chest irradiation, explaining probably why some groups report small rates of complete response. 
Moreover, the recent development of MRI that could reveal smaller asymptomatic brain metastases will require an update of these trials in the next few years. Indeed, in contrast to prior literature which showed a prevalence of brain metastases at presentation of $10 \%$, Hochstenbag et al found a prevalence of $24 \%$. This difference can been explained by the fact that the prevalence of $10 \%$ is based on clinical signs and confirmation by brain imaging and, that in the Hochstenbag's study, MRI diagnosed $15 \%$ brain metastases in neurologically asymptomatic patients [31].

The neuropsychological toxicity of PCI was only described in retrospective studies performed with a small number of patients. In our review, two randomised trials reported neuropsychological assessments that was performed only in a part of the patients and during the first years following PCI. They provided no data about longterm toxicity. It should be noted that other factors than radiotherapy toxicity can also contribute to neurological complications. Indeed old age, alcohol, anticancer drugs (vincristine, etoposide,...), paraneoplastic encephalomyelitis [32;33] and tobacco long-term use or can produce demential syndromes. Concomitant administration of some types of chemotherapy is considered to contribute to brain radiotherapy toxicity. The fractionation and the total dose of radiotherapy delivered to the brain can also influence the toxicity. Neurological toxicity may be reduced by using $2 \mathrm{~Gy}$ fractions ( 20 to $40 \mathrm{~Gy}$ ) and by giving PCI after chemotherapy. All these factors were not analysed in our systematic review because of a total lack of data in the report of the results of the individual randomised trials.

In conclusion, the present systematic review indicates that PCI decreases brain metastases incidence and that PCI improves survival in SCLC patients in CR after chemotherapy. These effects were obtained in patients who had no systematic neuropsychological brain imagery assessments. The long-term toxicity has so far not been prospectively evaluated. If PCI can be recommended in patients with SCLC and CR documented by a workup including brain CT scan, data are lacking to generalise its use to any CR situations as some would like [34]. Particularly the potential benefits of PCI have to be carefully balanced with the possible long-term effects, in patients who are managed with more modern imagery techniques like MRI. New trials, adapted to these new developments, are necessary.
Table 4: Subgroup meta-analysis: role of $\mathrm{PCl}$ on survival ( I I studies evaluable)

\begin{tabular}{lcc}
\hline & $\mathrm{n}$ studies & $\mathrm{HR}$ \\
\hline & & \\
Initial PCl & 5 & $\mathrm{I} .00(0.91-1.09)$ \\
Limited disease & 5 & $0.98(0.90-1.07)$ \\
All stages diseases & 6 & $0.84(0.72-0.98)$ \\
Brain CT scan for staging & 4 & $0.82(0.68-0.98)$ \\
Brain CT scan before randomisation & 2 & $0.78(0.62-0.98)$ \\
No CT scan before randomisation & 2 & $0.96(0.88-1.04)$
\end{tabular}

\section{Appendix A: ELCWP Quality Score}

The attributed value per item is 2 points if it is clearly defined in the article, 1 point if its description is uncomplete or unclear and o point if it is not defined or inadequate.

\section{A. Protocol Design \\ 1. definition of the number of participating centres}

2. selection criteria:

- PS

- age

- disease stage

- other anticancer treatment

- comorbidity

- histology

3. randomisation method

4. treatment description

- PCI : total dose, fractions, duration, fields, kind of energy

- dose adaptation plan

5. work-up :

- initial : brain CT scan or MRI and/or neuropsychological assessment

- at response assessment (idem) 
- during follow-up after therapy (idem)

- brain CT scan or MRI : systematically or not

6. evaluation criteria

- brain metastases free duration

- survival

- toxicity

- neuropsychological assessment

7. statistical methods

- primary and secondary objectives definition

- statistical methods and tests used

- a priori estimate of sample size

B. Analysis Performance

1. analysis timing

- dates of first and last patient registration

- type of analysis (definitive or planned interim)

2. patients characteristics

- ineligibility rate (per arm)

- causes for ineligibility

- eligible patients characteristics :

- age

- performance status

$-\operatorname{sex}$

- disease extent or stage

- neuropsychological assessment

- time to PCI

- chemotherapy description

- arms balance according to stratification

3. survival
- rates

- crude numbers of deaths

- confidence intervals on rates

- statistical tests results

- intent to treat analysis

4. brain metastases incidence

- rates

- crude numbers of deaths

- confidence intervals on rates

- statistical tests results

- intent to treat analysis

5. neurologic toxicity

- descriptions per arm

- unassessable rate

- statistical tests results

- confidence intervals on rates

6. prognosis factor for survival

- univariate analysis

- multivariate analysis

7. prognosis factor for brain metastases

- univariate analysis

- multivariate analysis

8. discussion

- authors conclusions in accordance with results

- for negative trials : a posteriori estimate of study power

Acknowledgements

B Martin received a fellowship of a FNRS-Televie grant 7.45 12.98. Belgium. 


\section{References}

I. Paesmans M, Sculier JP, Lecomte J, Thiriaux J, Libert P, Sergysels R, , et al: Prognostic factor for patients with small cell lung cancer. Cancer 2000, 89:523-33

2. Komaki R, Cox JD, Whitson W: Risk of brain metastases from small-cell carcinoma of the lung related to the length of survival and prophylactic irradiation. Cancer Treat $\operatorname{Rep} 1981$, 65:8| $1-14$

3. Nugent JL, Bunn PA, Matthews MJ, Ihde DC, Cohen MH, Gazdar A, et al: CNS metastases in small cell bronchogenic carcinoma. Cancer 1979, 44:1885-93

4. Aupérin A, Arriagada R, Pignon JP, Le Péchoux C, Grégor A, Stephens RJ, Kristjansen PEG, et al: Prophylactic cranial irradiation for patients with small-cell lung cancer in complete remission. New Engl J Med I999, 34 I:476-83

5. Johnson BE, Becker B, Goff WB, Petronas N, Krehbiel MA, Makuch RW, et al: Neurologic, neuropsychologic, and computed cranial tomography scan abnormalities in 2- to 10 -year survivors of small cell lung cancer. I Clin Oncol 1985, 3:1659-67

6. Lee JS, Umsawasdi T, Lee YY, Barkley Jr HT, Murphy WK, Welch S, et al: Neurotoxicity in long-term survivors of small cell lung cancer. Int J Radiat Oncol Biol Phys 1986, I 2:3 I3-2I

7. Chak LY, Zatz LM, Wasserstein P, Cox RS, Kushlan PD, Porzig KJ, et al: Neurologic dysfunction in patients treated for small cell carcinoma of the lung: a clinical and radiological study. Int J Radiat Oncol Biol Phys 1986, I 2:385-89

8. Fonseca R, O'Neill BP, Foote RL, Grill JP, Sloan JA, Frytak S: Cerebral toxicity in patients treated for small cell carcinoma of the lung. Mayo Clin Proc 1999, 74:46I-65

9. Laukkanen E, Klonoff H, Allan B, Graeb D, Murray N: The role of prophylactic brain irradiation in limited stage small cell lung cancer: clinical, neuropsychologic, and CT sequelae. Int J Radiat Oncol Biol Phys 1988, I 4: I 109-17

10. Licciardello JTW, Cersosimo RJ, Karp DD, Hoffer SM, Paquette-Tello DA, Ki Hong W: Disturbing central nervous system complications following combination chemotherapy and prophylactic whole-brain irradiation in patients with small cell lung cancer. Cancer Treat Rep 1985, 69:1429

II. Van Oosterhout AGM, Boon PJ, Houx PJ, Ten Velde GPM, Twijnstra $A$ : Follow-up of cognitive functioning in patients with small cell lung cancer. Int | Radiat Oncol Biol Phys 1995, 3 I:9 I I- |4

12. Chalmers TC, Smith H Jr, Blackburn B, Silverman B, Schoeder B, Reitman $D$, et al: $A$ method for assessing the quality of a randomised clinical trial. Control Clin Trials |98।, 2:3 I-49

13. Sculier JP, Berghmans T, Castaigne C, Luce S, Sotiriou C, Vermylen P, Paesmans $M$ : Maintenance chemotherapy for small cell lung cancer: a critical review of the literature. Lung Cancer 1998, | 9:|4|-5|

14. Luce S, Paesmans M, Berghmans T, Castaigne C, Sotiriou C, Vermylen $P$, et al: Revue critique des études randomisées évaluant lerôle de la radiothérapie adjuvante à la chimiothérapie dans le traitement du cancer bronchique à petites cellules au stade limité. Rev Mal Resp 1998, 15:633-4I

15. Mascaux C, Paesmans M, Berghmans T, Branle F, Lafitte J], Lemaître $F$, et al: A systematic review of the role of etoposide and cisplatin in the chemotherapy of small cell lung cancer with methodological assessment and meta-analysis. Lung Cancer 2000, 30:23-36

16. Arriagada R, Le Chevalier T, Borie F, Rivière A, Chomy P, Monnet I, et al: Prophylactic cranial irradiation for patients with smallcell lung cancer in complete remission. J Natl Cancer Inst. 1995, 87: $183-90$

17. Laplanche A, Monnet I, Santos-Miranda JA, Bardet E, Le Péchoux C, Tarayre $M$, et al: Controlled clinical trial of prophylactic cranial irradiation for patients with small-cell lung cancer in complete remission. Lung Cancer 1998, 21:193-201

18. Jackson DV Jr, Richards II F, Cooper R, Ferree C, Muss HB, Douglas $\mathrm{R}$, et al: Prophylactic cranial irradiation in small cell carcinoma of the lung. JAMA 1977, 237:2730-33

19. Gregor A, Cull A, Stephens RJ, Kirkpatrick JA, Yarnold JR, Girling DJ, et al: Prophylactic cranial irradiation is indicated following complete response to induction therapy in small cell lung cancer: results of a multicentre randomised trial. Eur ] Cancer 1997, 33:1752-58

20. Eagan RT, Frytak S, Lee RE, Creagan ET, Ingle JN, Nichols WC: A case for preplanned thoracic and prophylactic whole brain radiation therapy in limited small-cell lung cancer. Cancer Clin Trials I98I, 4:26I-6

21. Seydel HG, Creech R, Pagano M, Salazar O, Rubin P, Concannon J, et al: Prophylactic versus no brain irradiation in regional small cell lung carcinoma. Am J Clin Oncol 1985, 8:218-23

22. Hansen HH, Dombernowsky P, Hirsch FR, Hansen M, Rygard J: Prophylactic irradiation in bronchogenic small cell anaplastic carcinoma. A comparative trial of localized versus extensive radiotherapy including prophylactic brain irradiation in patients receiving combination chemotherapy. Cancer 1980, 46:279-84

23. Ohonoshi T, Ueoka H, Kawahara S, Kiura K, Kamei H, Hiraki Y, et al: Comparative study of prophylactic cranial irradiation in patients with small cell lung cancer achieving a complete response: a long-term follow-up result. Lung Cancer 1993, 1 0:47-54

24. Beiler DD, Kane RC, Bernath AM, Cashdollar R: Low dose elective brain irradiation in small cell carcinoma of the lung. Int J Radiat Oncol Biol Phys 1979, 5:941-45

25. Niiranen A, Holsti $P$, Salmo M: Treatment of small cell lung cancer. Acta Oncol 1989, 28:501-505

26. Maurer LH, Tulloh M, Weiss RB, Blom J, Leone L, Glidewell O, et al: $A$ randomized combined modality trial in small cell carcinoma of the lung. Comparison of combination chemotherapyradiation therapy versus cyclophosphamide-radiation therapy effects of maintenance chemotherapy and prophylactic whole brain irradiation. Cancer 1980, 45:30-39

27. Aisner J, Whitacre M, Van Echo DA, Wiernik PH: Combination chemotherapy for small cell carcinoma of the lung: continuous versus alternating non-cross-resistant combinations. Cancer Treat Rep 1982, 66:221-30

28. Stewart LA, Parmar MKB: Meta-analysis of the literature or of individual patient data: is there a difference? Lancet 1993, 34I:4I8-22

29. Mulrow CD: The Medical Review Article: State of the Science. Ann. Intern. Med. 1987, I 06(3):485-8

30. Egger M, Zellweger-Zahner T, Schneider M, Junker C, Lengeler C, Antes $G$ : Language biases in randomised controlled trials published in English and German. Lancet 1997, 350:326-29

31. Hochstenbag MMH, Twijnstra A, Wilmink JT, Wouters EFM, ten Velde GPM: Asymptomatic brain metastases (BM) in small cell lung cancer: MR-imaging is useful at initial diagnosis. J NeuroOncol 2000, 48:243-248

32. Greenlee JE, Boyden JW, Pingree M, Brashear HR, Clawson SA, Keeney PM: Antibody Types and IgG Subclasses in Paraneoplastic Neurological Syndromes. J. Neurol. Sci. 200I, I 84(2): I-3

33. Kleopa KA, Teener JW, Scherer SS, Galetta SL, Bird SJ: Chronic Mutiple Paraneoplastic Syndromes. Muscle Nerve 2000 , 23(I I): I767-72

34. Lebeau B: Medical ethics and therapeutic progress: the example of lung cancer. Hippocrates to the rescue! Lung Cancer 2000, 30:9-13

\section{Pre-publication history}

The pre-publication history for this paper can be accessed here:

http://www.biomedcentral.com/content/backmatter/ 1471-2407-1-5-b1.pdf 